\title{
Examining the Relationship Between the Achievement Goals and Teacher Engagement of Turkish Teachers
}

\author{
Berna Ürün Karahan \\ Correspondence: Berna Ürün Karahan, Department of Educational Sciences, Kafkas University, Merkez-Kars, Turkey.
}

Received: January 11, 2018

doi:10.11114/jets.v6i3.2919
Accepted: February 11, $2018 \quad$ Online Published: February 17, 2018

URL: https://doi.org/10.11114/jets.v6i3.2919

\begin{abstract}
The aim of this study is to determine the level of achievement goals and teacher engagement of Turkish teachers and the relationship between them if any. Accordingly, the study was conducted with Turkish teachers working in an eastern city and its districts and villages in the school year of 2017-2018. The data were collected using " $3 \times 2$ Achievement Goal Questionnaire for Teachers" adapted into Turkish by Yerdelen and Padır (2017) and "Engaged Teachers Scale" developed by Yerdelen, Klassen and Durksen (2017). Sixty eight Turkish teachers participated in the study. According to the obtained results, it was determined that achievement goals and teacher engagement of Turkish teachers were moderate in general. In addition, it was found that the variable of gender did not show any significant difference and there were significant correlations between the achievement goals and teacher engagement. Finally, achievement goals was a predictor of teacher engagement; on the other hand, working year and type of school studied did not predict teacher engagement.
\end{abstract}

Keywords: Turkish teacher, profession, engagement, achievement goal, relationship

\section{Introduction}

Achievement affects the entire life of individual not only in the educational process, but also afterwards. In fact, individual's existence in social life, self-realization as an individual and appreciation by society are related to this concept. However, it may not be possible to succeed in every area. Because individual differences and the differences of goals requested to be achieved also change the direction of the concept of achievement. Achievement goal, on the other hand, "signifies individual's orientation and determination to use her or his time and energy for achieving goals that have specified standards. Achievement motivation is the motivation of idealizing the tasks of learning. This motivation arises from the need of achievement" (Küçükoğlu, Kaya, and Turan, 2010: 122).

The objective of the educational process is to raise successful individuals. Thus, the concept of achievement goals has become one of important subjects emphasized in recent years (Özdemir, 2016). Because achievement goals, which are effective in individuals "reaching the result and displaying the expected behavioral change, can still lead them to compatible and incompatible attitudes" (Üzbe and Bacanl1, 2015: 36).

"Achievement goals are a very recent study area examining the criteria and standards regarding individuals' learning studies and trying to determine what kind of a meaning they attribute to learning" (Akın and Arslan, 2014: 267). The concept of achievement goal is generally encountered under two titles: 1) learning orientation (developing a talent that already exists), 2) performance orientation (proving oneself and avoiding failure) (Dweck and Leggett, 1988). The most important factor affecting the learning and academic attitudes of students is achievement goals (Özgüngör, 2014). It is possible to assert that students with learning orientation make an effort for having a command of educational materials and the subject (Pajares and Cheong, 2003) and students with performance orientation rather try to be compared with their peers and do better than others (Ames, 1992; Elliot and Church, 1997; Jagacinski and Strickland, 2000; Pintrich, 2000; Urdan, 1997).

Teachers, on the other hand, are the keystone of the educational process and the education system (Alpaslan, Bozgeyikli, and Avc1, 2017). It is required to examine carefully the effect of achievement goals of teachers, who will manage and direct the process, on their teacher engagement. Because the most important concepts for the educational process have been goal orientation and achievement motivation, recently (Kaplan and Maehr, 2006).

"Occupational engagement is defined as engagement to occupation and occupational career and self-commitment to occupation and occupational career and belief in occupational ethics and occupational objectives and accepting them" 
(Lachman and Aranya, 1986:228; cited by Aslan, 2008). According to another definition; engagement is "the level of importance attached by the individual to her or his occupation in life depending on gaining expertise" (Aslan, 2008: 165). Engagement enables teachers to love their job, work willingfully, establish healthy relationships with their students, and conduct the educational process successfully.

Occupational commitment is generally mentioned with 3 sub-dimensions as affective, normative and continuity. "While an individual with high affective commitment and/or normative commitment is more interested in following the developments in her or his occupation, attending relevant unions, and being a participant; an individual with high continuity commitment is less oriented to attending occupational behaviors" (Meyer, Allen and Smith, 1993: 540). In Turkey, acquiring an occupation is usually considered equal to having an income. However, every individual needs to do a job that she or he desires and may succeed in. That is the actual way of having a positive result. In other words, an individual is supposed to devote herself or himself to the occupation and its consequences instead of considering it only an instrument of making money (Benligiray and Sönmez, 2011; Özdevecioğlu and Aktaş, 2007). Because occupational commitment, which is different from work commitment, enables the individual to realize the central position of her or his occupation in life as a result of gaining expertise in a certain area and making an effort for this (Baysal and Paksoy, 1999).

Another factor of occupational commitment is the achievement goals of teachers. The subject of the study is the achievement goals of teachers and how they differ in terms of the variables of working year or type of school worked. The reason why the engagement of Turkish teachers and their commitment in this process are examined importantly is that they will teaching Turkish language with which we communicate and which we use as a tool to protect and convey our history and culture and keeps a nation together. In addition, even though student motivation and achievement goals are considerably studied in the literature, it is possible to assert that achievement goals of teachers is ignored (Yerdelen and Padır, 2017).

\section{Method}

This study was conducted in the correlational research model to determine the achievement goals and engagement of Turkish teachers. "Correlational research is studies conducted for determining the relationships between two or more variables and obtaining clues about the cause and effect" (Büyüköztürk, Çakmak, Akgün, Karadeniz, and Demirel, 2011:14).

\subsection{Sample Group}

The sample group consisted of 68 Turkish teachers who were assigned to the public schools in the eastern provinces, randomly selected year of 2017-2018. Table 1 shows information about the demographic characteristics of the teachers.

Table 1. Demographic characteristics of the teachers in the sample group

\begin{tabular}{|c|c|c|c|}
\hline $\begin{array}{l}\text { Demographic } \\
\text { Characteristics }\end{array}$ & Frequency (f) & & Percentage (\%) \\
\hline \multirow{3}{*}{ Gender } & Female & 42 & 61.8 \\
\hline & Male & 26 & 38.2 \\
\hline & Total & 68 & 100.0 \\
\hline \multirow{5}{*}{ Working Year } & 1 (recent) & 22 & 32.4 \\
\hline & $2(2-3)$ & 21 & 30.8 \\
\hline & $3(3-5)$ & 12 & 17.6 \\
\hline & $4(5-7)$ & 13 & 19.1 \\
\hline & Total & 68 & 100.0 \\
\hline \multirow{4}{*}{$\begin{array}{l}\text { School They Worked } \\
\text { at }\end{array}$} & 1(village) & 18 & 26.5 \\
\hline & 2 (district) & 23 & 33.8 \\
\hline & 3(city center) & 27 & 39.7 \\
\hline & Total & 68 & 100.0 \\
\hline
\end{tabular}

\subsection{Data Collection Tools}

\subsubsection{Achievement Goal Questionnaire}

The scale was developed by Elliot, Murayama, and Pekrun (2011) for students. Then, it was translated into French by Macret, Elliot and Cury (2015) and adapted for measuring the achievement goals of teachers and they conducted its 
validity-reliability study. It is adapted to Turkish by Yerdelen and Padır (2017).As a consequence, they revealed that the Achievement Goal Questionnaire addressing achievement goals according to the $3 \times 2$ model based on confirmatory factor analysis and reliability analysis, was also a valid and reliable assessment tool for teachers. The scale involves 18 items and 6 subscales. These subscales are called as "task-approach", "task-avoidance", "self-approach", "self-avoidance", "other-approach" and "other-avoidance". The seven-point Likert scale is scored as; 1-strongly disagree, 2-disagree, 3-mildly disagree, 4-undecided, 5-mildly agree, 6-agree, and 7-strongly agree. According to the subscales, the Cronbach's alpha reliability coefficients of the scale were determined as follows; task-approach .71, task-avoidance .77 , self-approach .82 , self-avoidance .71 , other-approach .85 , and other-avoidance .84 . The obtained CFA results were $\left(\chi^{2}(120, \mathrm{~N}=207)=281.03, \mathrm{p}<.05, \mathrm{RMSEA}=.08, \mathrm{NNFI}=.95, \mathrm{CFI}=.96, \mathrm{IFI}=.96, \mathrm{~S}-\mathrm{RMR}=.047\right)$, all of which prove that the assessment tool is valid and reliable.

\subsubsection{Engaged Teachers Scale}

Developed by Klassen, Yerdelen, and Durksen (2013); the scale consists of 16 items and 4 subscales. These subscales are emotional engagement, cognitive engagement, social engagement: colleagues, and social engagement: students. It is a seven-point Likert scale and scored as; 0-never, 1-almost never, 2-rarely, 3-sometimes, 4-frequently, 5-usually, and 6-always. The Cronbach's alpha reliability coefficients of the the subscales were calculated as follows; cognitive engagement .84, emotional engagement .87, social engagement: students .83 and social engagement: colleagues .79. The CFA results of the scale were determined as; $\left(\chi^{2}(100)=296.94, p<.05\right.$; CFI $=.97$; GFI $=.89$; NFI $=.95$; RMSEA $=.08 ; 90 \% \mathrm{CI}=.07, .09)$.

\section{Findings}

In the study, the level of achievement goals and engagement of Turkish teachers was examined through their mean values. Table 2 shows the results.

Table 2. Means

\begin{tabular}{llll}
\hline Variables & $\mathrm{N}$ & $\overline{\mathrm{X}}$ & $\mathrm{Ss}$ \\
\hline TA & 68 & 12.17 & 2.22 \\
$\mathrm{TAv}$ & 68 & 14.73 & 2.51 \\
$\mathrm{SA}$ & 68 & 11.94 & 2.70 \\
$\mathrm{SAv}$ & 68 & 13.41 & 2.35 \\
$\mathrm{OA}$ & 68 & 9.97 & 2.20 \\
$\mathrm{OAv}$ & 68 & 12.08 & 2.41 \\
$\mathrm{EE}$ & 68 & 14.85 & 3.57 \\
$\mathrm{Se}-\mathrm{c}$ & 68 & 16.47 & 3.75 \\
$\mathrm{Bb}$ & 68 & 14.45 & 3.47 \\
$\mathrm{Se}-\mathrm{s}$ & 68 & 12.35 & 2.64 \\
\hline
\end{tabular}

The highest and lowest scores to be obtained from the task-approach (TA) subscale of the Achievement Goal Questionnaire are 21 and 3, respectively. When examining the mean scores, it can be stated that the teachers obtained moderate scores from this subscale. The highest and lowest possible scores to be obtained from the task-avoidance (TAv) subscale of the questionnaire are 21 and 3, respectively. When examining the mean scores, it can be asserted that the teachers had high scores from this subscale. The highest and lowest scores to be obtained from the self-approach (SA) subscale of the questionnaire are 21 and 3, respectively. When examining the mean scores, it can be stated that the teachers obtained moderate scores from this subscale. The highest and lowest scores to be obtained from the self-avoidance (SAv) subscale of the questionnaire are 21 and 3, respectively. When examining the mean scores, it can be asserted that the teachers obtained moderate scores from this subscale. The highest and lowest scores to be obtained from the other-approach $(\mathrm{OA})$ subscale of the questionnaire are 21 and 3, respectively. When examining the mean scores, it can be stated that the teachers had low scores from this subscale. The highest and lowest scores to be obtained from the other-avoidance (OAv) subscale of the questionnaire are 21 and 3, respectively. When examining the mean scores, it can be stated that the teachers obtained moderate scores from this subscale. On the other hand, the highest and lowest scores to be obtained from the emotional engagement (ee) subscale of the Engaged Teachers Scale are 24 and 0 , respectively. When examining the mean scores, it can be asserted that the teachers had high scores from this subscale. The highest and lowest scores to be obtained from the social engagement: colleagues (Se-c) subscale of the scale are 24 and 0 , respectively. When examining the mean scores, it can be stated that the teachers had high scores from this 
subscale. The highest and lowest scores to be obtained from the cognitive engagement (ce) subscale of the scale are 24 and 0 , respectively. When examining the mean scores, it can be stated that the teachers had high scores from this subscale. Finally, the highest and lowest scores to be obtained from the social engagement: students (Se-s) subscale of the scale are 24 and 0 , respectively. When examining the mean scores, it can be asserted that the teachers obtained moderate scores from this subscale.

In the study, Pearson correlation coefficients were calculated for examining the relationship between the achievement goals and engagement of Turkish teachers. Table 3 shows the results.

Table 3. Correlations

\begin{tabular}{lrrrrll}
\hline Variables & $\mathbf{2}$ & $\mathbf{3}$ & $\mathbf{4}$ & $\mathbf{5}$ & $\mathbf{6}$ & $\mathbf{7}$ \\
\hline 1. TA &,- 074 &, $495^{* *}$ &,$- 387^{* *}$ &, $345^{* *}$ & $-520^{* *}$ &, $715^{* *}$ \\
2. TAv & &,- 086 &, $308^{*}$ &,- 195 &,- 210 &, $372^{* *}$ \\
3. SA & & &,$- 450^{* *}$ &, $495^{* *}$ & $-569^{* *}$ &, $714^{* *}$ \\
4. SAv & & & &,$- 569^{* *}$ &, $393^{* *}$ &,$- 747^{* *}$ \\
5. OA & & & & &,$- 286^{*}$ &, $732^{* *}$ \\
6. OAv & & & & &,$- 570^{* *}$ \\
7. teacher & & & & & \\
engagement & & & &
\end{tabular}

When examining the correlation coefficients, it was observed that there was a positive high correlation between teacher engagement and achievement goals. Upon examination of Table 3: this correlation was seen between the teacher engagement and the other-approach $(\mathrm{OA})\left(\mathrm{r}=.732^{* *}\right)$ subscale of the achievement goal questionnaire, also between the teacher engagement and the task-approach $(\mathrm{TA})\left(\mathrm{r}=.715^{* *}\right)$ subscale of the achievement goal questionnaire and between the teacher engagement and the self-approach (SA) $\left(\mathrm{r}=.714^{* *}\right)$ subscale of the achievement goal questionnaire. In addition, a negative high correlation was found between teacher engagement and achievement goals. The correlation was observed between teacher engagement and self-avoidance (SAv) $(\mathrm{r}=-.747 *$ ). On the other hand, when examining Table 3; it was determined that there were a negative moderate correlation between teacher engagement and other-avoidance $(\mathrm{OAv})\left(\mathrm{r}=-, 570^{* *}\right)$ subscale of achievement goals and a positive weak correlation between teacher engagement task- avoidance (TAv) $\left(\mathrm{r}=, 372^{* *}\right)$ subscale of achievement goals. Additionally, it was determined that there were various correlations among the subscales of the achievement goal questionnaire. When examining the table; it was observed that these correlations were negatively moderate between self-avoidance (SAv) and other-approach $(\mathrm{OA})(\mathrm{r}=$ ,$\left.- 569^{* *}\right)$, between self-approach (SA) and other-avoidance (OAv) $\left(\mathrm{r}=-.569^{* *}\right)$, and between task-approach (TA) and other-avoidance $(\mathrm{OAv})\left(\mathrm{r}=-.520^{* *}\right)$. Apart from these, there was a positive weak correlation between task-approach (TA) and self-approach (SA) $\left(\mathrm{r}=.495^{* *}\right)$, between self-approach (SA) and other-avoidance (OAv) $\left(\mathrm{r}=.495^{* *}\right)$, between self-avoidance ( $\mathrm{SAv})$ and other-avoidance (OAv) $\left(\mathrm{r}=.393^{* *}\right)$, between task-approach (TA) and other-approach (OA) $\left(\mathrm{r}=.345^{* *}\right)$, and between task-avoidance (TAv) and self-avoidance $(\mathrm{SAv})\left(\mathrm{r}=.308^{*}\right)$. On the other hand, there was a negative weak correlation between task-approach (TA) and self-avoidance (SAv) $\left(\mathrm{r}=-.387^{* *}\right)$, between self-approach (SA) and self-avoidance (SAv) $\left(\mathrm{r}=-.450^{* *}\right)$, and between other-approach $(\mathrm{OA})$ and other-avoidance $(\mathrm{OAv})\left(\mathrm{r}=-.286^{*}\right)$.

Multiple linear regression analysis was conducted for determining whether the variables predicted each other or not. Table 4 shows the results.

Table 4. Results of multiple linear regression analysis

\begin{tabular}{|c|c|c|c|c|c|}
\hline Variables & $\beta$ & $\mathbf{F}$ & $\mathbf{R}$ & $\mathbf{R}^{2}$ & $\mathbf{p}$ \\
\hline TA & $.315^{*}$ & & & & \\
\hline TAv & $-.243 *$ & & & & \\
\hline SA & $.156^{*}$ & & & & \\
\hline SAv & $-.228 *$ & & & & \\
\hline $\mathrm{OA}$ & $.311^{*}$ & 125.41 & .972 & .944 & .000 \\
\hline OAv & $-.179 *$ & & & & \\
\hline How many years & -.031 & & & & \\
\hline Which school & .049 & & & & \\
\hline
\end{tabular}

When examining the data obtained as a result of multiple linear regression analysis in Table 4; the value of $\mathrm{p}=.000$ showed that the regression model was significant. The table shows that engagement of teachers was significantly predicted by their achievement goals. In terms of the value $\mathrm{R}^{2}$; it was found out that $94 \%$ of teacher engagement $\left(\mathrm{R}^{2}=.94\right)$ was predicted by the subscales of achievement goals. In terms of the standardized regression coefficients; the primary predictor of teacher engagement was the "TA (task-approach)" subscale of the achievement goal questionnaire $(\beta=.315)$. In addition, the "OA (other-approach)" $(\beta=.311)$ and "SA (self-approach)" $(\beta=.156)$ subscales were positive 
significant predictors of teacher engagement. On the other hand, the "TAv (task-avoidance)" ( $\beta=-.243)$, "SAv (self-avoidance)" ( $\beta=-.228)$ and "OAv (other-avoidance)" $(\beta=-.179)$ subscales were negative significant predictors of teacher engagement. Finally, teachers' working year $(\beta=-.031)$, and type of school $(\beta=.049)$ were not significant predictors of teacher engagement.

\section{Conclusion and Discussion}

The study tried to examine the relationship between the achievement goals and engagement of Turkish teachers. For this purpose, it was primarily tried to determine the level of achievement goals and engagement of the teachers. According to the results, it was observed that achievement goals of teachers was high in some subscales of the questionnaire, and moderate and low in some other subscales of the achievement goal questionnaire. Accordingly, it was determined that achievement goals of Turkish teachers was lower than the expected in the subscale of "trying to fulfil a task properly". On the other hand, the teachers were at expected level in the subscale of "avoiding to fail in fulfilling a task properly". It is important for teachers to abstain from fulfilling a task wrongly or failing to fulfil it. This is because their effort of trying to fulfill their tasks properly will cause them to also have proper results. On the other hand, it was seen that teachers obtained moderate results from the self-approach and self-avoidance subscales. According to this result, it is possible to state that teachers are oriented to "fulfil a task better than the former one and avoid fulfilling it in a worse way", which is a desired result. Finally, it was determined that they obtained a lower result in the other-approach subscale than expected, had negative views about "fulfilling a task better than others" and obtained an almost bad result. On the other hand, the moderate result obtained from the other-avoidance subscale was lower than the expected, which showed that teachers avoided "fulfilling a task worse than others" and tried to obtain better results. On the other hand, the results obtained from the subscales of the Engaged Teachers Scale were at expected and desired level. According to this result, it was determined that engagement of Turkish teachers was positive in emotional-cognitive stages and from the teacher-student perspective. As a result of the study conducted by Çetin, Cihangiroğlu and Türk (2010) with a group of pharmacists; they determined that engagement of the pharmacists was high in general.

In the study, it was determined that there was a positive high correlation between engagement and achievement goals of Turkish teachers. This correlation was observed between the teacher engagement and the other-approach, task-approach and self-approach subscales of the achievement goal questionnaire. According to this result, it is possible to state that teachers who wanted to fulfil a task or a work better than others and to be more successful than others had a higher teacher engagement than others. On the other hand, there was a negative high correlation between teacher engagement and achievement goals. This correlation was observed between teacher engagement and self-avoidance. According to this result, it was determined that as teachers' states of abstaining from a self-based incompetency and avoiding fulfilling a task worse than the former one increased, their engagement decreased. On the other hand, there were a negative moderate correlation between teacher engagement and the other-avoidance subscale of achievement goals and a positive weak correlation teacher engagement and the task-avoidance subscale of achievement goals. According to this result, it is possible to state that as teachers' state of avoiding fulfilling a task worse than others increased, their engagement decreased. In their study, Alpaslan, Bozgeyikli, and Avc1 (2017) concluded that as the learning-approach orientation of classroom teacher candidates increased, their occupational concerns decreased and as the learning-avoidance and performance-avoidance approach increased, their occupational concern level increased correspondingly. In the study by Aydin (2014) it was determined that there was a positive significant correlation between the learning orientation and academic self-efficacy of teacher candidates.

In the study, according to the results of regression analysis conducted for determining whether or not the variables predicted each other, it was determined that engagement of the Turkish teachers was significantly predicted by their achievement goals. According to these results, it is possible to state that the teachers who tried to fulfil a task properly and better than others and had a self-based competence were more successful than others. On the other hand, it can be asserted that the teachers who abstained from a self-based inadequacy, feel a self-based inadequacy and avoid fulfilling a task worse than the former one are more unsuccessful than others. In the study conducted by Alpaslan, Bozgeyikli and Avcı (2017): it was concluded that the increase of learning-approach orientation of classroom teachers decreased their occupational concerns, whereas as a result of the increase of learning-avoidance approach, their occupational concerns increased. As a result of the study by Özdemir (2016), it was determined that achievement goals of teacher candidates were predicted by personal characteristics like achievement, engagement and autonomy. In the study conducted by Çetin, Cihangiroğlu and Türk (2010) with pharmacists it was determined that there was no significant difference between age and duration of working at profession and engagement. 


\section{References}

Akın, A., \& Arslan, S. (2014). The relationships between achievement goal orientations and determination. Education and Science, 39(175), 267-274.

Ames, C. (1992). Classrooms: Goals, structures, and student motivation. Journal of Educational Psychology, 84(3), 261-271. https://doi.org/10.1037/0022-0663.84.3.261

Aslan, Ş. (2008). Examining the Relationships between Organizational Citizenship Behavior and Organizational and Professional Commitment, Management and Economics, The Journal of Celal Bayar University, Faculty of Economics and Administrative Sciences, 15(2), 163-178.

Aydın, S. (2014). İnvestigation of the relationship between preservice science teachers achievement goal orientations and academic self-efficacy with structural equation model. Turkish Studies, 9(2), 221-230. https://doi.org/10.7827/TurkishStudies.6338

Baysal, A. C., \& Paksoy, M. (1999). The Meyer-Allen model inmultidimensional examination of professional and organizational commitment. The Journal of I.U. Faculty of Business Administration, 28(1), 7-15.

Benligiray, S., \& Sönmez, H. (2011). Relationships of nurses’ professional commitment with other commitment forms: organizational commitment, work commitment, and family commitment. The Nursing Journal ofHacettepe UniversityFaculty of Health Sciences, 28-40.

Büyüköztürk, Ş., Çakmak, K. E., Akgün, E. Ö., Karadeniz, Ş., \& Demirel, F. (2011). Scientific Research Methods. Publications of Pegem Academy. Ankara.

Çetin, M., Cihangiroğlu, N., \& Türk, Y. Z. (2010). Examination of professional commitment perceptions of a group of pharmacists. Pamukkale Medical Journal, 3(3), 125-130.

Dweck, C. S., \& Leggett, E. L. (1988). A social-cognitive approach to motivation and personality. PsychologicalReview, 95(2), 256-273. https://doi.org/10.1037/0033-295X.95.2.256

Elliot, A. J., \& Church, M. A. (1997). A hierarchical model of approach and avoidance achievement motivation. Journal of Personality and Social Psychology, 72, 218-232. https://doi.org/10.1037/0022-3514.72.1.218

Elliot, A. J., Murayama, K., \& Pekrun, R. (2011). A 3 x 2 achievement goal model. Journal of Educational Psychology, 103(3), 632-648. https://doi.org/10.1037/a0023952

Gözler, A., Bozgeyikli, H., \& Avcı, A. (2017). An investıgaton of prımary school pre-servıce teachers' achıevement goal orientations and occupational concerns. Abantizzet Baysal University Journal of Education Faculty, 17(1), $189-211$. https://doi.org/10.17240/aibuefd.2017.17.28551-304629

Jagacinski, C. M., \& Strickland, O. J. (2000). Task and ego orientation the role of goal orientations in anticipated affective reactions to achievement outcomes. Learningand Individual Differences, 12, 189-208. https://doi.org/10.1016/S1041-6080(01)00037-1

Kaplan, A., \& Maehr, M. L. (2007). The contribitions and prospects of goal orientation theory. Educ. Psychol. Rev., 19, 141-184. https://doi.org/10.1007/s10648-006-9012-5

Küçükoğlu, A., Kaya, H. İ., \& Turan, A. (2010). The Analysis of the Candidate of the Primary Teacher's Perception Orientation of Success in Terms of Different Variations (Atatürk University and Ondokuz Mayıs University Sample). Firat University Journal of Social Sciences, 20(2), 121-135.

Lachman, R., \& Aranya, N. (1986). Evaluation of Alternative Models of Commitments and Job Attitudes of Professionals, Journal of Occupational Behaviour, (7), 227-243.

Mascret, N., Elliot, A. J., \& Cury, F. (2015). The $3 \times 2$ achievement goal questionnaire for teachers. Educational Psychology, 37(3), 346-361. https://doi.org/10.1080/01443410.2015.1096324

Meyer, J. P., Allen, N. J., \& Smith, C. A. (1993). Commitment to Organizations and Occupations: Extension and Test of a Three-Component Conceptualization, Journal of Applied Psychology, (78), 538-551. https://doi.org/10.1037/0021-9010.78.4.538

Özdemir, S. (2016). The role of psychological needs and personality traits of preservice teachers in predicting their achievement goals. The Journal of Mehmet Akif Ersoy University Faculty of Education, 1(40), 1-19.

Özdevecioğlu, M., \& Aktaş, A. (2007). The effect of career commitment, professional commitment and organizational commitment on life satisfaction: the role of work-family conflict. Erciyes University,Faculty of Economics and Administrative Sciences, 28, 1-20. 
Özgüngör, S. (2014). Relationship between 1dentity statuses and goal orientations based on university Students Self Esteem Levels. Pamukkale University Journal of Education Faculty, 35(35), 33-46. https://doi.org/10.9779/PUJE543

Pajares, F., \& Cheong, Y. F. (2003). Achievement goal orientations in writing: A developmental perspective. International Journal of Educational Research, 39, 437-455. https://doi.org/10.1016/j.ijer.2004.06.008

Pintrich, P. R. (2000). An achievement goal theory perspective on issues in motivation terminology, theory, and research. Contemporary EducationalPsychology, 25, 92-104. https://doi.org/10.1006/ceps.1999.1017

Urdan, T. (1997). Achievement goals and the orientation of friends toward school in early adolescence. Contemporary Educational Psychology, 22, 165-191. https://doi.org/10.1006/ceps.1997.0930

Üzbe, N., \& Bacanl1, H. (2015). The role of achievement goal orientation, self esteem and academic achievement in prediction of self handicapping, The Journal Of Turkish Educational Sciences, 13(1), 33-50. Retrieved from http://dergipark.gov.tr/tebd/issue/26087/274923

Yerdelen, S., \& Padır, M. A. (2017). Adaptation of $3 \times 2$ achievement goal questionnaire for teachers into Turkısh: validity and reliability study. Bartin University Journal of Faculty of Education, 6(3), 1053-1065.

Yerdelen, S., Durksen, T., \& Klassen, R. M. (2017). Measuring Turkish teachers' work engagement: Adaptation of engaged teacher scale. Paper presented at the Annual Meeting of American Educational Research Association (AERA). San Antonio, TX, USA.

\section{Copyrights}

Copyright for this article is retained by the author(s), with first publication rights granted to the journal.

This is an open-access article distributed under the terms and conditions of the Creative Commons Attribution license which permits unrestricted use, distribution, and reproduction in any medium, provided the original work is properly cited. 